\title{
Who Is the Free Rider in the Drop-Shipping Supply Chain?
}

\author{
Li Feng \\ School of Management, University of Science and Technology of China, Hefei, P.R.China \\ Email: lifeng86@mail.ustc.edu.cn \\ Tu Yijian and Guo Xiaolong \\ School of Management, University of Science and Technology of China, Hefei, P.R.China \\ Email: \{tuyijian,gxl\}@mail.ustc.edu.cn
}

\begin{abstract}
In Drop-shipping supply chain, retailers get the customer orders and manufacturers carry out the orders. Are there any free riders while obtaining the customer order? If any, who could be the free riders? By comparing the decentralized and centralized decision making, we find that both manufacturers and retailers are possible to behave as free riders. Also, we study the contract designs to coordinate manufacturers and retailers in Drop-shipping supply chain, and we find that a combination of quantity discount and delivery reliability compensation mechanism as to guarantee manufacturers a safe delivery can achieve the bi-direction excitation, and finally the coordination of the supply chain.
\end{abstract}

Index Terms-direct distribution model, Drop-shipping, free rider, bi-direction excitation, quantity discount, compensation mechanism

\section{I . INTRODUCTION}

As the development of information technology and internet, more and more customers choose to buy things from on-line shops, because of their convenience and abundant production types. According to the statistics from Chinese B2B Research Center, the total trading volume of Chinese electronic commerce market researched 4,500 billion CNY in 2010, and the number of net shopping customers surpass 0.13 billion CNY in China. The online channel through internet has become one of the most important distribution channels of many companies, and is still developing at an extraordinary speed.

Online channels bring out the Drop-Shipping channel, where the online retailers get customer orders and manufactures undertake the task of production and delivery, as shown in Fig. 1. In the Drop-shipping channel, suppliers are responsible for both storage and delivery, while retailers only have to concentrate on marketing. Direct delivery channels can not only cause the inventory pooling and scale economies effect, but also increase the categories of products on sale [1]. As a result, the order fulfillment pattern of Drop-shipping is very popular in the electronic commerce field, and arouses much attention from many corporations. A survey said $56 \%$ of manufacturers received a Drop-shipping request from online retailers, and among them, 30.6\% treat Drop-shipping as their main order fulfillment pattern, meanwhile, another $44.5 \%$ consider it as an important alternative [2].

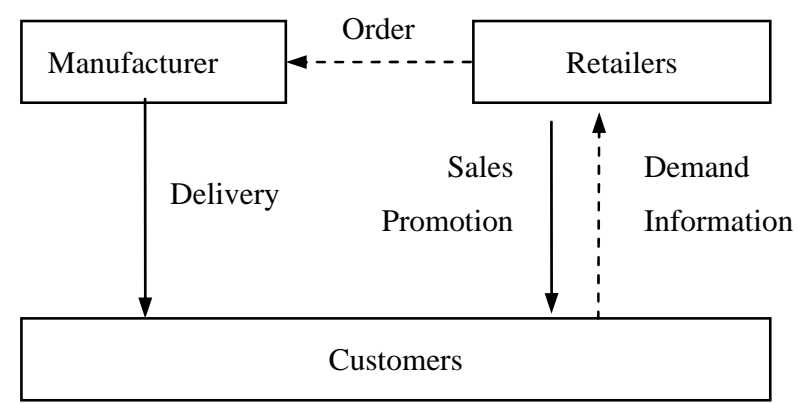

Figure 1. Drop-shipping Supply Chain 
Compared to the traditional two-level online delivery channel, one distinguishing characteristic of Drop-shipping channel is that manufacturers contact customers directly, and by controlling the delivery reliability, manufacturers can influence the demand of the channel, moreover, the delivery service plays a critical part in customer satisfaction[3][4]. Delivery reliability indicates the ratio of the number of deliveries meeting the requirements of customers to the total number of deliveries in a period [4]. Based on the hypothesis that the delivery reliability of manufacturers and sales efforts of retailers can both influence the decisions of customers, this research is aimed to found out the inefficiency of this new supply chain, and then the coordination mechanism.

\section{II . Literature REVIEW}

As the application of Drop-shipping becomes wider and wider, relevant researches increase, which mainly focus on the application and coordination mechanism design of Drop-shipping channel, the sale channel or inventory location choice.

For the retailer, Drop-shipping has significant advantages which include lower holding, handling, and shortage costs. In other hand, Drop-shipping increased per-unit cost, made the delivery more difficulty when a single order involves products from different manufacturers, and may caused longer delivery times. Khouja [6] [7] design an optimal mix strategy and two (Q, $\mathrm{R}$ ) inventory models in order to capture the advantages of dropping and avoid many of its shortcomings. For retailer, Bailey et al. [2] consider how dynamically to manage inventory to fill the order and put forward the optimal channel strategy for retailers, by analyzing the change of their market share and product popularity. Ayanso et al. [8] also research how to use Drop-shipping as an order fulfillment option. They developed a Monte Carlo simulation model to found that retailers fulfilled advanced orders through the traditional channel, while lower level orders through the Drop-shipping channel. Netessine et al. [9] found that the supply chain under the drop-shipping arrangement benefits from risk pooling because the inventory for multiple retailers is stocked at the same location, and a mixed channel could be made by combining the Drop-shipping with the traditional channel.
Combine traditional channel, affiliate programs and drop-shipping, Xiao et al. [10] analyzed the optimal inventory strategy and admission policies for a "Clicks-and-Bricks" retailer that sold through its own physical and online stores by means of affiliate programs and drop-shipping agreement. Hovelaque et al. [11] assess different forms of existing organizations: "store-picking”, “drop-shipping” and "dedicated warehouse-picking” by using a newsboy order policy model and note the impact of some paremeters on inventory and flow management policies throughout the supply chain, particularly those linked to the size of the internet market in relation to traditional market size market demand hazards.

As the inventory decision and stock keeping responsibility transferring to manufacturer when supply chain choose Drop-shipping only, Lee et al.[12] found that retailers' profit might reduce while manufacturers' might increase in the Drop-shipping channel, by comparing the payoffs of retailers and manufactures in both traditional and Drop-shipping channel.

In the coordination mechanism design aspect, Netessine et al. [13] proposed a new coordination scheme, where a compensation plan was used and the wholesaler subsidized a part of the retailer's marketing expenses; Gan et al. [14] realized that commitment-penalty contracts could effectively solve the inefficiency aroused by asymmetric information in Drop-shipping supply chain.

Above-mentioned research are all based on the assumption that demands of customers are exogenetic or they depend on sales efforts, while ignore the impact on online delivery reliability through internet. Yao et al. [1] considered the impact on customer decision from delivery reliability, and analyzed information sharing was effective in coordinating the supply chain, however, they didn't involve the influence of sales efforts to demands of customers. Based on the former research on the decision characteristic of online channel customer, this article analyses the efficiency and coordination mechanism of Drop-shipping channel, under the condition that the customer decision is influenced by both sales effort and delivery reliability.

As we know, online channel and traditional channel provide different shopping experience during different 
shopping period. Therefore, online retailers can free ride off of the promotional effort exerted by traditional channel retailers. Baal et al. [15] used empirical data to determine the magnitude of both effects in two directions: from online retailers to traditional retailers and vice versa, and found that over $20 \%$ of customers are free riders and that retailers retain substantially fewer customers in both directions. In this setting, Carlton et al. [16] suggests manufacturers should use various mechanisms to limit online sale, particularly when online retailers offer deep discounts, by examining three categories of products: fragrances DVD players, and side-by-side refrigerators. During a single transaction, customers may obtain services from more than one channel including traditional channel and online channel, so they would became free rider. Maybe, we don't feel surprise about Carlton's result, because of free riding hurting the retailer that provides that service, but Shin [17] showed analytically that free riding also can benefits the retailer that provides the service when customers are heterogeneous in terms of their opportunity costs for shopping, and regarded the free riding as a important way to prevent an aggressive response from another retailer and reduces the intensity of price competition.

Bernsterin et al. [18] discussed the free riding between manufacturer's direct channel and retailer's channel and found out an interesting result: a manufacturer may purposely induce free riding by setting up a direct traditional channel to design multi-channel supply chain. The direct channel allows customers to experience the product, and then manufacturer anticipate their purchase at a retail store. That article examines how the free riding phenomenon affects a manufacturer's supply chain structure decision when there are fixed plus incremental variable costs for operating the direct store.

Although Bernsterin et al. researched the free riding between manufacturer and retailer, the multi-channel was considered. In our article, we focus on the free riding between manufacture and retailer in Drop-shipping channel alone, and we have not find other paper about free ridding in Drop-shipping.

\section{MODEL}

In the internet background, this article studies the contract design of Drop-shipping supply chain consisting of single manufacturer and single retailer. The manufacturer is the only supplier, and the retailer doesn't hold any storage, since the products are delivered to customers directly by the manufacturer. As a result, the market demand of the whole supply chain is influenced by both sales effort and delivery reliability. It's supposed that the price of products is external variable, shared by manufacturer and retailer.

The decision order in this supply chain is, at first, the manufacturer gives the wholesale price, and then, the retailer and manufacturer decide their own sales effort and delivery reliability respectively.

Expressions used in this article and their operational definitions are as follows,

$A_{r}$ : Sales effort of the retailer

$\alpha$ : Cost coefficient for sales effort

$A_{m}$ : Delivery reliability of the manufacturer

$\beta$ : Cost coefficient for delivery reliability

$P$ : Product price

$W:$ Wholesale price (per product)

$c$ : Production cost

$D:$ Market demand of the products

$\pi_{r}$ : Profits of the retailer

$\pi_{m}$ : Profits of the manufacturer

$\pi_{t}$ : Profits of the whole supply chain

Based on the demand function developed by the first and sixth article in the reference list, we presume that the demand function is $\alpha\left(A_{r}^{s_{t}}\right)^{2} / 2$, given the sales effort level $A_{r}$, and the cost function is $\beta\left(A_{m}^{s_{I}}\right)^{2} / 2$, given the delivery reliability level $A_{m}$, and finally the demand function of the Drop-shipping channel is,

$$
D=1+A_{r}+A_{m}
$$

\section{Model Analyzes}

In order to set a benchmark, this paper supposes that the manufacturer and retailer are integrated as a firm, and all decisions are made by the firm. And this decision scenario is a sublimate scenario, under which the profit of the supply chain gets the optimal outcome. And in order to differentiate the decentralized scenario in the next segment, this paper uses $s_{1}$ as a superscript stands for the centralized scenario, and $s_{2}$ for the decentralized one. Hence, the profit function of the supply chain is as 
follows,

$$
\pi_{t}^{s_{I}}=(P-c)\left(1+A_{r}^{s_{I}}+A_{m}^{s_{I}}\right)-\alpha\left(A_{r}^{s_{I}}\right)^{2} / 2-\beta\left(A_{m}^{s_{I}}\right)^{2} / 2
$$

The first order conditions of $A_{r}$ and $A_{m}$ on $\pi_{t}^{s_{l}}$ are as follows,

$$
\begin{aligned}
& \frac{\partial \pi_{t}^{s_{I}}}{\partial A_{r}^{s_{I}}}=P-c-\alpha A_{r}^{s_{I}}=0 \\
& \frac{\partial \pi_{t}^{s_{I}}}{\partial A_{m}^{s_{I}}}=P-c-\beta A_{m}^{s_{I}}=0
\end{aligned}
$$

Since the second order derivative of $A_{r}$ and $A_{m}$ on $\pi_{t}^{s_{l}}$ are $-\alpha$ and $-\beta$, respectively, according to equations (3) and (4), we can obtain the optimal sales effort $A_{r}^{s_{1} *}$ and the optimal delivery reliability $A_{m}^{s_{1} *}$ as follows where the ${ }^{*}$ stands for the optimal solution.

$$
\begin{aligned}
A_{r}^{s_{1} *} & =\frac{P-c}{\alpha} \\
A_{m}^{s_{1} *} & =\frac{P-c}{\beta}
\end{aligned}
$$

Substituting equations (5) and (6) in to (1) and (2), we obtain the following equations,

$$
\begin{aligned}
D^{s_{I^{*}}} & =1+\frac{(P-c)(\alpha+\beta)}{\alpha \beta} \\
\pi_{t}^{s^{*}} & =(P-c)+\frac{(P-c)^{2}(\alpha+\beta)}{2 \alpha \beta}
\end{aligned}
$$

\section{A. The centralized scenario}

In order to set a benchmark, this paper supposes that the manufacturer and retailer are integrated as a firm, and all decisions are made by the firm. And this decision scenario is a sublimate scenario, under which the profit of the supply chain gets the optimal outcome. And in order to differentiate the decentralized scenario in the next segment, this paper uses $s_{1}$ as a superscript stands for the centralized scenario, and $s_{2}$ for the decentralized one. Hence, the profit function of the supply chain is as follows,

$$
\pi_{t}^{s_{I}}=(P-c)\left(1+A_{r}^{s_{I}}+A_{m}^{s_{I}}\right)-\alpha\left(A_{r}^{s_{I}}\right)^{2} / 2-\beta\left(A_{m}^{s_{I}}\right)^{2} / 2
$$

The first order conditions of $A_{r}$ and $A_{m}$ on $\pi_{t}^{s_{I}}$ are as follows,

$$
\begin{aligned}
& \frac{\partial \pi_{t}^{s_{I}}}{\partial A_{r}^{s_{I}}}=P-c-\alpha A_{r}^{s_{I}}=0 \\
& \frac{\partial \pi_{t}^{s_{I}}}{\partial A_{m}^{s_{I}}}=P-c-\beta A_{m}^{s_{I}}=0
\end{aligned}
$$

Since the second order derivative of $A_{r}$ and $A_{m}$ on $\pi_{t}^{s_{l}}$ are $-\alpha$ and $-\beta$, respectively, according to equations (3) and (4), we can obtain the optimal sales effort $A_{r}^{s_{1} *}$ and the optimal delivery reliability $A_{m}^{s_{1}{ }^{*}}$ as follows where the * stands for the optimal solution.

$$
\begin{aligned}
A_{r}^{s_{1} *} & =\frac{P-c}{\alpha} \\
A_{m}^{S_{1} *} & =\frac{P-c}{\beta}
\end{aligned}
$$

Substituting equations (5) and (6) in to (1) and (2), we obtain the following equations,

$$
\begin{gathered}
D^{s_{l^{*}}}=1+\frac{(P-c)(\alpha+\beta)}{\alpha \beta} \\
\pi_{t}^{s_{I^{*}}}=(P-c)+\frac{(P-c)^{2}(\alpha+\beta)}{2 \alpha \beta}
\end{gathered}
$$

\section{B. The decentralized scenario}

In the decentralized scenario, the manufacturer and retailer make their decisions according to their own profit functions. And the profit functions are as follows,

$$
\begin{aligned}
& \pi_{r}^{s_{2}}=\left(P-W^{s_{2}}\right)\left(1+A_{r}^{s_{2}}+A_{m}^{s_{2}}\right)-\alpha\left(A_{r}^{s_{2}}\right)^{2} / 2 \\
& \pi_{m}^{s_{2}}=\left(W^{s_{2}}-c\right)\left(1+A_{r}^{s_{2}}+A_{m}^{s_{2}}\right)-\beta\left(A_{m}^{s_{2}}\right)^{2} / 2
\end{aligned}
$$

The backward induction is adopted to solve the game between the manufacturer and retailer. In the second stage, the manufacturer and retailer decide the optimal delivery reliability and sales effort, respectively, under a given wholesale price $W^{s_{2}}$. According to the first order conditions, we obtain the optimal sales effort of the retailer and the optimal delivery reliability of the manufacturer as follows,

$$
\begin{aligned}
& A_{r}^{s_{2} *}=\frac{P-W^{s_{2}}}{\alpha} \\
& A_{m}^{s_{2} *}=\frac{W^{s_{2}}-c}{\beta}
\end{aligned}
$$

With the response function of the second stage, in the first stage, the manufacturer determines the optimal wholesale price for its unit product to the retailer. Submit equations (11) and (12) into (10), then the first and second order derivatives of $W^{s_{2}}$ on $\pi_{m}^{s_{2}}$ are as follows,

$$
\begin{gathered}
\frac{\partial \pi_{m}^{s_{2}}}{\partial W^{s_{2}}}=1+\frac{P+c-2 W^{s_{2}}}{\alpha}+\frac{W^{s_{2}}-c}{\beta} \\
\frac{\partial^{2}\left(\pi_{m}^{s_{2}}\right)}{\partial\left(W^{s_{2}}\right)^{2}}=\frac{-2}{\alpha}+\frac{1}{\beta}
\end{gathered}
$$

Let equation (13) to be zero, i.e., from the first order condition, we obtain the optimal wholesale price,

$$
W^{s_{2} *}=\frac{(P+c+\alpha) \beta-c \alpha}{2 \beta-\alpha}
$$

To make the model analysis sense, according to the assumption: $c<W^{s_{2}}<P$, there is $\beta>\alpha$ and $P-c>\frac{\alpha \beta}{\beta-\alpha}$ required. 
Submitting (15) into (11) and (12), the following equations exists,

$$
\begin{gathered}
A_{r}^{s_{2} *}=\frac{(P-c)(\beta-\alpha)-\alpha \beta}{\alpha(2 \beta-\alpha)} \\
A_{m}^{s_{2} *}=\frac{P-c+\alpha}{2 \beta-\alpha}
\end{gathered}
$$

And then from equations (1), (9), (10), (15), (16) and (17), there are,

$$
\begin{gathered}
D^{s_{2} *}=\frac{(P-c+\alpha) \beta}{\alpha(2 \beta-\alpha)} \\
\pi_{r}^{s_{2}^{*} *}=\frac{((P-c)(\beta-\alpha)-\alpha \beta)((P-c)(\beta+\alpha)+3 \alpha \beta)}{2 \alpha(\alpha-2 \beta)^{2}} \\
\pi_{m}^{s_{2} *}=\frac{(P-c+\alpha)^{2} \beta}{2 \alpha(2 \beta-\alpha)}
\end{gathered}
$$

Through the analyses of the centralized and decentralized scenarios, we have the following proposition.

Proposition 1: The optimal sales effort, the optimal delivery reliability, the production demand and the total profit of the supply chain are all greater in the centralized scenario, i.e., the manufacturer and retailer are both free riders in the drop-shopping supply chain.

\section{V . Contract Design}

Under the decentralize scenario, the Drop-shipping can not achieve the optimization, existing room for improvement. So as to coordinate manufacture and retailer, and implement Pareto optimality, in this part, we try to discuss a contract.

In general, quantity discount and compensate are used for solving the supply chain coordination. We also resolve the free riding problem in dint of these two ways.

\section{A. Quantity Discount Contract}

Through the quantity discount contract, the retailer can obtain some price discount depend on how much product bought from the manufacture. More quantity ordered by the retailer, much less price the retailer will get. Therefore the manufacture can inspire the retailer. Quantity discount contract is composed of two parts: fixed wholesaler price and dynamic favorable price depend on order quantity.

In the traditional supply chain contract designing, quantity discount contract is generally used to arm at the demand uncertainty. In Drop-shipping channel, due to manufacture bears all the demand uncertainty, the quantity discount has another effect on the supply chain.
The discount could encourage retailer enhance her sale effort which will increase the market demand and increase the order quantity of retailer. So we choose discount quantity contract to solve free ridding in Drop-shipping supply chain.

This article uses $s_{3}$ as a superscript stands for the scenario Drop-shipping supply chain adopts discount quantity contract. When denoting $\left(W^{s_{3}}, t^{s_{3}} D^{s_{3}}\right)$ for quantity discount contract, $W^{s_{3}}$ stands for fixed price that is decided by manufacture, $t^{s_{3}}$ stands for price discount factor that is negotiated by manufacture and retailer depend on market demand $D^{s_{3}}$. We obtain manufacture's and retailer's profit functions,

$$
\begin{aligned}
\pi_{r}^{s_{3}}= & \left(P-W^{s_{3}}+t^{s_{3}}\left(1+A_{r}^{s_{3}}+A_{m}^{s_{3}}\right)\right)\left(1+A_{r}^{s_{3}}+A_{m}^{s_{3}}\right) \\
& -\alpha\left(A_{r}^{s_{3}}\right)^{2} / 2 \\
\pi_{m}^{s_{3}}= & \left(W^{s_{3}}-t^{s_{3}}\left(1+A_{r}^{s_{3}}+A_{m}^{s_{3}}\right)-c\right)\left(1+A_{r}^{s_{3}}+A_{m}^{s_{3}}\right) \\
& -\beta\left(A_{m}^{s_{3}}\right)^{2} / 2
\end{aligned}
$$

The backward induction is adopted to solve the game between the manufacturer and retailer. We can obtain following conclusion.

Proposition 2: The free ridding of Drop-shipping supply chain can not be solved by quantity discount contract.

Prove: in the second stage, according to the first order conditions, we obtain the optimal sales effort of the retailer and the optimal delivery reliability of the manufacturer as follows,

$$
\begin{aligned}
A_{r}^{s_{3} *} & =\frac{\left(P-W^{s_{3}}\right) \beta+2 t^{s_{3}}(P-c+\beta)}{2 t^{s_{3}}(\alpha-\beta)+\alpha \beta} \\
A_{m}^{s_{3} *} & =\frac{W^{s_{3}} \alpha-2 t^{s_{3}}(P-c+\alpha)-c \alpha}{2 t^{s_{3}}(\alpha-\beta)+\alpha \beta}
\end{aligned}
$$

With the response function of the second stage, in the first stage, the manufacturer determines the optimal wholesale price for its unit product to the retailer. Submit equations (23) and (24) into (22), then we obtain the optimal wholesale price of manufacture as follows, $W^{s_{3} *}=\frac{-\alpha \beta(P+\alpha)\left(2 t^{s_{3}}+\beta\right)+c\left(\alpha \beta(\alpha-\beta)+2 t^{s_{3}}\left(\alpha^{2}-\alpha \beta+\beta^{2}\right)\right)}{2 t^{s_{3}}(\alpha-\beta)^{2}+\alpha \beta(\alpha-2 \beta)}$

Submit equation (25) into (23), and let equation (23) equal to $A_{r}^{s_{s} *}$ stands for centralize scenario. And then we obtain the $t^{s_{3}}$ expression as following,

$$
t^{s_{3}^{*}}=\frac{\beta(\alpha-\beta)(P-c)+\alpha \beta^{2}}{2(P-c+\beta)(\beta-\alpha)}
$$

Submit equations (25) and (26) into (24), the following equation exists, 


$$
A_{m}^{s_{3}^{*}}=0
$$

Therefore, the quantity discount contract does not achieve Pareto optimality.

\section{B. Combination Mechanism}

According to the part 4, we know both manufacture and retailer are free riders. Using quantity discount contract achieve unidirectional excitation only, absolutely quantity discount contract can not solve Drop-shipping free ridding problem. We will design a bi-direction excitation mechanism to coordination the supply chain.

When manufacture attends to acquire customers demand in Drop-shipping supply chain, to inspire the manufacture and retailer simultaneously, we combine the delivery reliability compensation with quantity discount contract.

This article uses $s_{4}$ as a superscript stands for the scenario Drop-shipping supply chain adopts the combination of discount quantity contract and delivery reliability compensation. Denoting $\left(W^{s_{4}}, t^{s_{4}} D^{s_{4}}, k^{s_{4}}\right)$ for the combination mechanism, $W^{s_{4}}$ stands for fixed price that is decided by manufacture, $t^{s_{4}}$ stands for price discount factor that is negotiated by manufacture and retailer depend on market demand $D^{s_{4}}, k^{s_{4}}$ stands for delivery reliability compensation hat is negotiated by manufacture and retailer. We obtain manufacture's and retailer's profit functions as following,

$$
\begin{aligned}
\pi_{r}^{s_{4}}= & \left(P-W^{s_{4}}+t^{s_{4}}\left(1+A_{r}^{s_{4}}+A_{m}^{s_{4}}\right)\right)\left(1+A_{r}^{s_{4}}+A_{m}^{s_{4}}\right) \\
& -\alpha\left(A_{r}^{s_{4}}\right)^{2} / 2-k A_{m}^{s_{4}} \\
\pi_{m}^{s_{4}}= & \left(W^{s_{4}}-t^{s_{4}}\left(1+A_{r}^{s_{4}}+A_{m}^{s_{4}}\right)-c\right)\left(1+A_{r}^{s_{4}}+A_{m}^{s_{4}}\right) \\
& -\beta\left(A_{m}^{s_{4}}\right)^{2} / 2+k A_{m}^{s_{4}}
\end{aligned}
$$

The backward induction is adopted to solve the game between the manufacturer and retailer. We can obtain following conclusion.

Proposition 3: The combination mechanism of delivery reliability compensation and quantity discount contract solves free ridding of Drop-shipping supply chain and achieve Pareto optimality.

Prove: The backward induction is adopted to solve the game between the manufacturer and retailer. In the second stage, the manufacturer and retailer decide the optimal delivery reliability and sales effort, respectively, under a given wholesale price $W^{s_{2}}$. According to the first order conditions, we obtain the optimal sales effort of the retailer and the optimal delivery reliability of the manufacturer as follows,

$$
\begin{aligned}
A_{r}^{s_{4} *} & =\frac{\left(P-W^{s_{4}}\right) \beta+2 t^{s_{4}}(P-c+\beta-k)}{2 t^{s_{4}}(\alpha-\beta)+\alpha \beta} \\
A_{m}^{s_{4} *} & =\frac{\alpha\left(W^{s_{4}}-c-k\right)-2 t^{s_{4}}(P-c+\alpha-k)}{2 t^{s_{4}}(\alpha-\beta)+\alpha \beta}
\end{aligned}
$$

With the response function of the second stage, in the first stage, the manufacturer determines the optimal wholesale price for its unit product to the retailer. Submit equations (30) and (31) into (29), then we obtain the optimal wholesale price of manufacture as follows,

$$
\begin{aligned}
W^{s_{4} *}= & \frac{-\alpha\left(2 t^{s_{4}}+\beta\right)((P+\alpha) \beta-k \alpha)}{2 t^{s_{4}}(\alpha-\beta)^{2}+\alpha \beta(\alpha-2 \beta)} \\
& +\frac{c\left(\alpha \beta(\alpha-\beta)+2 t^{s_{4}}\left(\alpha^{2}-\alpha \beta+\beta^{2}\right)\right)}{2 t^{s_{4}}(\alpha-\beta)^{2}+\alpha \beta(\alpha-2 \beta)}
\end{aligned}
$$

Submit equation (32) into (30) and (31), and let equations (23) and (24) equal to $A_{r}^{s_{1}^{*}}$ and $A_{m}^{s_{1} *}$ stand for centralize scenario. And then we obtain $k^{s_{4} *}$ and $t^{s_{3}}$ expressions as following,

$$
\begin{gathered}
k^{s_{4} *}=P-c \\
t^{s_{4} *}=\frac{\alpha \beta}{2(\beta-\alpha)}
\end{gathered}
$$

Submit equations (32), (33) and (34) into (30) and (31). And then we obtain the new expressions of $A_{r}^{s_{4} *}$ and $A_{m}^{s_{4} *}$ as following,

$$
\begin{aligned}
A_{r}^{s_{4} *} & =\frac{P-c}{\alpha} \\
A_{m}^{s_{4} *} & =\frac{P-c}{\beta}
\end{aligned}
$$

Submit equation (32) to equation(33) into equations (28) and (29), and sum them as following,

$$
\pi_{r}^{s_{4} *}+\pi_{m}^{s_{4} *}=(P-c)+\frac{(P-c)^{2}(\alpha+\beta)}{2 \alpha \beta}
$$

Comparing equations (35), (36) and (37) with (5), (6) and (8), we should know the combination mechanism of delivery reliability compensation and quantity discount contract achieves Pareto optimality. On the other hand, to make sure that both manufacture and retailer increase profit and accept the new contract, we can induct a fixed compensation $f$ between manufacture and retailer. In some case, $f$ expresses the compensation from manufacture to retailer, and in some case, the other way round. That depends on the profit change of original contract and new contract. We do not discuss in this article.

\section{CONCLUSION}


The online channel provides the firms with wider market space, and has become an important distribution channel of many firms. Having a boosting development, it's playing an significant role in the business activity. As a kind of the online channel, the Drop-shipping online channel has been applied broadly because of scale economies and risk aggregation effect. Based on the separated stages of the order obtainment and fulfillment in the Drop-shipping channel, this article analyzed its coordination mechanism.

By comparing the decentralized and centralized decision making, we found free riders were common and that both manufacturers and retailers were possible to behave as free riders. Then, we discovered that using quantity discount alone couldn't solve the coordination problem, because both manufacturers and retailers deeded incentive contract. As a result, this article designed a combination mechanism of quantity discount and compensation mechanism as to guarantee manufacturers a safe delivery in order to achieve the coordination of the supply chain.

The preconditions of this article are certain demands, certain prices and information symmetry. Further research will remove these preconditions and consider more complex scenarios.

\section{REFERENCES}

[1] D.Q. Yao, H. Kurata and S.K. Mukhopadhyay, "Incentives to reliable order fullfillment for an internet drop-shipping supply chain”, International Journal of Production Economics, Vol. 113, pp.324-334, 2008.

[2] J.P. Bailey, and E.Rabinnovich, "Internet book retailing and supply chain management: an analytical study of inventory location speculation”, Transportation Research Part E: Logistics and Transportation Review, pp.159-177, 2005.

[3] E. Rabinovich, M. Rungtusanatham and T.M. Laseter, "Physical distribution service performance and internet retailer margins: The drop-shipping context”, Journal of Operations Management, Vol 26, pp767-780, 2008.

[4] K.Y Chen, M. Kaya, O.Ozer, "Dual Sales channel management with service competition”, Manufacturing \& Service Operations Management, Vol. 10, pp. 654-675, 2008.
[5] A. Parasuraman, V.A. Zerthaml and A. Malhotra, "E-S-QUAL: A multiple-item scale for assessing electronic service quality”, Journal of Service Research, Vol. 7, pp. 213-233, 2005.

[6] M. Khouja, "The evaluation of drop shipping option for e-commerce retailers”, Computers \& Industrial Engineering, Vol. 41, pp. 109-126, 2001.

[7] M. Khouja, A.C Stylianou, “A (Q, R) inventory model with a drop-shipping option for e-business”, Omega, Vol. 39, pp. 896-908, 2009.

[8] A. Ayanso, M. Diaby and S.K. Nair, "Inventory rationing vis drop-shipping in internet retailing: A sensitivity analysis”, European Journal of Operation Research, Vol. 171, pp. 135-152, 2006.

[9] S. Netessine and N. Rudi, "Supply chain choice on the internet”, Management Science, Vol. 52, pp. 844-864, 2006.

[10] Y.B. Xiao, F.Y. Chen, and J.Chen, "Optimal inventory and dynamic admission policies for a retailer of seasonal products with affiliate programs and drop-shipping”, Naval Research Logistics, Vol. 56, pp. 300-317, 2009.

[11] V. Hovelaque, L.G. Soler and S. Hafsa, "Supply chain organization and e-commerce: a model to analyze store-picking, warehouse- picking and drop-shipping.”, 4OR: A Quarterly Journal of Operations Research, Vol. 5, pp. 143-155, 2007.

[12] C.C Lee and W.H.J. Chu, "Who should control inventor in a supply chain?”, European Journal of Operation Research, Vol. 164, pp. 158-172, 2005.

[13] S. Netessine and N. Rudi, "Supply chain structures on the internet and the role of marketing-operations interaction", Chapter 14 in Handbook of Quantitative Supply Chain Analysis, 2004.

[14] X. Gan, S.P. Sethi and J. Zhou, “Commitment-penalty contracts in drop-shipping supply chains with asymmetric demand information”, European Journal of Operational Research, Vol. 204, pp. 449-462, 2010.

[15] S.V. Baal, and C. Dach, "Free riding and customer retention across retailers' channels”, Journal of Interactive Marketing, Vol. 19, pp. 75-85, 2005.

[16] D.W. Carlton, and A. Chevalier, "Free riding and Sales Strategies For the Internet”, The Journal of Industrial Economics, Vol. XLIX, pp. 0022-1821, 2001. 
[17] J. Shin, "How Does Free Riding on Customer Service Affect Competition”, Marketing Science, Vol. 26, pp. 488-503, 2007.

[18] F. Bernstein, J.S Song and X. Zheng, "Free riding in a Multi-Channel Supply Chain”, Naval Research Logistics, Vol. 56, pp. 745-765, 2009.

Feng Li was born in Wuxi City in China on 23 July, 1986, is a Ph.D candidate in management science and engineering at University of Science and Technology of China(USTC, Hefei, China) now, and got his bachelor's degree of business administration at Nanjing University of Aeronautics and Astronautics(NUAA, Nanjing, China) in 2008.

He is working and studying as a research intern in the office of development and planning at USTC since 2008. He has published three Chinese papers on China Higher Education Research and Studies in Science of Science. His current research interests are general strategy and management science.

Yijian Tu was born in Zhangzhou City in china on 30 December, 1985, is Master candidate in management science and engineering at University of Science and Technology of China (USTC, Hefei, China) now, and got his bachelor's degree of business administration at Northern China Electronic Power University in 2008.

His current research interests are dual channel management and online channel management.

Xiaolong Guo was born in Weifang China on 25 February, 1986, is a Ph.D candidate of the School of Management at the University of Science and Technology of China (USTC, Hefei, China) now, and got his bachelor's degree in Management from Northeastern University (NEU, Shenyang, China) in 2008. His research interests are supply chain management and tourism management.

He has published two papers in the past 3 years, one on the 2009 International Conference on Computational Intelligence and Software Engineering and the other is on Journal of China Tourism Research.

Mr. Guo is a peer reviewer of European Journal of Operational Research (EJOR). 